\title{
O pito (de) holandês: cachimbos arqueológicos de caulim do Recife e de Salvador
}

The Dutch tobacco pipe: archaeological clay pipes from Recife and Salvador

\author{
Sarah Barros Viana Hissa (1) \\ Universidade Federal do Rio de Janeiro. Rio de Janeiro, Rio de Janeiro, Brasil
}

\begin{abstract}
Resumo: Os cachimbos europeus de caulim, produzidos especialmente entre os séculos XVII e XIX, eram industrializados e descartados rapidamente. Ainda, os estilos decorativos e de marcas de fabricante foram vários e relativamente bem marcados no tempo. Portanto, são particularmente úteis como instrumento de datação de sítios, camadas e feições, mesmo daqueles estratos urbanos extremamente revolvidos. Serão aqui analisados cachimbos de caulim exumados do Recife Antigo, Pernambuco, e da área de aterro à frente da Sé Primacial de Salvador, Bahia. Em um primeiro momento, explora-se o potencial desses cachimbos de caulim para aferir o período e o local de sua produção; consequentemente, também intervalos prováveis para os estratos de onde provieram. Nesse sentido, busca-se contribuir com uma arqueologia das cidades do Recife e de Salvador. Por outro lado, lembra-se que esses implementos do fumo se referiam a uma prática, então crescentemente globalizada, repleta de significados e associações socioculturais. Os casos aqui abordados, apesar de referirem-se a duas áreas urbanas distintas, possibilitam correlações interessantes, por serem ambas cidades portuárias de relevo na América portuguesa dos séculos XVII e XVIII. Considerando-se esses elementos, aventam-se algumas possibilidades interpretativas acerca das categorias sociais que os utilizaram, tendo em vista especialmente as investidas e as ocupações batavas do Nordeste.
\end{abstract}

Palavras-chave: Arqueologia urbana. Arqueologia histórica no Nordeste. Análise de cultura material. Método em arqueologia. Cachimbos de caulim. Cronologia relativa.

Abstract: European tobacco pipes made of white clay, mainly between the seventeenth and nineteenth centuries, were mass produced and discarded quickly. They came in various decorative styles and bore different makers marks which have been relatively well dated. As a result, they are particularly useful in dating sites, layers, and features, even in heavily disturbed urban strata. This article analyzes pipes excavated from the Brazilian colonial cities of Recife and Salvador. Initially, we explore how these kaolin pipes can be identified in terms of their origin and production dates, consequently dating their strata; this contributes to the archaeology of these cities. At the same time, these implements were related to the increasingly globalized practice of smoking, full of meanings as well as social and cultural associations. Although this particular case study describes different municipalities, some interesting correlations are possible, since both were significant ports in seventeenth and eighteenth century Portuguese America. With these elements in mind, we present some interpretive possibilities related to the use of these pipes.

Keywords: Urban Archaeology. Historical archaeology in Brazilian northeast region. Material culture analysis. Method in archaeology. Clay tobacco pipes. Relative chronology.

HISSA, Sarah Barros Viana. O pito (de) holandês: cachimbos arqueológicos de caulim do Recife e de Salvador. Boletim do Museu Paraense Emílio Goeldi. Ciências Humanas, Belém, v. 14, n. 3, p. 963-979, set.-dez. 2019. DOI: http://dx.doi.org/10.1590/1981.81222019000300014. Autora para correspondência: Sarah Barros Viana Hissa. Universidade Federal do Rio de Janeiro. Parque Quinta da Boa Vista, São Cristóvão. Rio de Janeiro, RJ, Brasil. CEP 20940-040 (sarah.hissa@gmail.com).

Recebido em 04/12/2018

Aprovado em 27/02/2019 


\section{INTRODUÇÃO}

O tempo médio que comumente se estima decorrer entre manufatura do cachimbo de caulim, sua importação, uso e descarte é de um a dois anos (Hume, 2001; Sudbury; Gerth, 2011). Somado a esse caráter descartável do cachimbo, lembra-se que sua produção foi intensa (estima-se que, no século XVIII, então já com o auxílio da gin-press, um fabricante habilidoso conseguiria produzir cerca de 500 cachimbos de haste longa por dia). Considerando-se esses dados, os cachimbos de caulim abrem uma janela para discutir uma série de questões sobre práticas cotidianas, com grande potencial de precisão cronológica (Hissa; Lima, 2017; Hissa, 2018). Este artigo apresentará algumas questões referentes a contextos urbanos, recuperados de vários logradouros do Recife Antigo, Pernambuco, e da Sé Primacial de Salvador, Bahia. Como o estudo dessas coleções, provenientes de aterramentos e de descartes nas áreas de uso público, refere-se à construção dos elementos estruturais daquela cidade e à consolidação de hábitos citadinos, esta pesquisa trata-se de produção voltada para 'arqueologia da cidade' (Staski, 1982; Symanski, 2003).

Schofield (1987) descreve os depósitos urbanos como de definição mais fácil do que os rurais, em razão da sua cor e de seu conteúdo, especialmente com materiais de eventos de demolição e por serem mais comumente relacionados a momentos específicos de deposição (como eventos de aterramento, construção e demolição). No entanto, apresentam também sequências complexas de camadas de formas e de dimensões variadas. Por outro lado, vislumbrando-se uma escala mais ampla, especialmente quando a cidade cresce ao redor do centro histórico, este se apresenta como o trecho da cidade de mais longa ocupação urbana ininterrupta, sofrendo crescentes pressões por espaço. Tais intensas alterações espaciais, tanto estratigráficas quanto arquitetônicas, induzem falar em palimpsesto e diacronia.

Os aterros históricos, particularmente interessantes para a discussão acerca da estratigrafia e da ocupação horizontal de contextos urbanos, podem ter sido formados a partir de episódios específicos e singulares de deposição ou a partir de deposições várias, graduais ou não, bem como podem incluir objetos e elementos com datações variadas e referentes a períodos amplos ou, ainda, associados a um intervalo cronológico praticamente pontual. No caso da área em frente à Sé Primacial de Salvador, há várias camadas de aterramento, estendendo o terreno à frente do adro. Os aterramentos feitos no Recife, tal como ocorre em várias cidades e áreas portuárias, foram acréscimos em direção às águas, marítimas ou fluviais, ampliando a terra firme ocupável. Várias das ruas recifenses de onde provieram os cachimbos de caulim setecentistas aqui em análise estavam sob águas no século XVII. Isso significa que estavam incluídos no depósito usado para alteamento e alargamento da costa.

Outra questão a se considerar, mesmo quando se trabalha com artefatos históricos provenientes de deposição in situ em logradouros públicos, é a relação interpretativa que se pode construir entre esses objetos e seus usuários. Ruas e praças públicas não se tratam de ambientes circunscritos e delimitados espacialmente, como é o caso de residências, tavernas ou escritórios administrativos, de modo que não se pode atribuir os achados a pessoas, famílias ou gestores públicos específicos. Algo que se pode fazer, que também foi o que se intentou neste trabalho, é compreender a trama urbana a partir das segmentações sociais que se instalam espacialmente na cidade. Nesse sentido, têm relevância interpretativa as áreas funcionais da cidade (como igrejas e áreas paroquiais, cemitérios, zonas portuárias, áreas industriais ou da administração pública, avizinhamento de imigrantes, trechos urbanos degradados ou de baixo ou alto status).

Além de relevar a importância e o potencial de tratar acervos gerados a partir de eventos ou processos pretéritos de aterramento e de apresentar algumas questões próprias da arqueologia urbana histórica, este artigo, a partir de dados históricos e elementos cronológicos e estilísticos dos cachimbos de caulim, também especula sobre as categorias socioculturais que os teria utilizado. Teriam sido os seus próprios produtores, os holandeses, que os utilizaram quando no Brasil ou, em alguma medida, eles foram aqui 
adotados pelos luso-brasileiros? Ainda, poderiam eles ter sido trazidos e utilizados aqui pelas categorias que mais transitavam entre continentes naquela época, os marinheiros?

\section{CIDADES PORTUÁRIAS, IMPORTAÇÕES E DISTRIBUIÇÃO DE CACHIMBOS NO RECIFE E EM SALVADOR}

Segundo William Dampier, viajante inglês que esteve no Brasil em 1699, os portos mais importantes no comércio internacional à época eram o da Baía de Todos os Santos, o de Pernambuco e o do Rio de Janeiro. A importância dos portos de Salvador e de Recife é reiterada em 1703 por um viajante cujo nome é desconhecido, e a dos três, por Le Gentil la Barbinais em 1714. Já no século XIX, no ano de 1800, John Turnbull aponta para a relevância dos portos de Salvador e do Rio de Janeiro, ditos como igualmente dinâmicos, porém já não mais mencionando o porto de Pernambuco. De fato, os portos mais importantes do período colonial para importação e exportação foram estabelecidos em Salvador, maior do Nordeste, Recife e Rio de Janeiro, maior do Sudeste. São Luís e Belém ganharam importância no século XVIII. No Sul do Brasil, teve importância significativa o porto de Rio Grande, especialmente na segunda metade do século XIX. Como importância terciária, ficam os de Santos, da Paraíba, de Fortaleza e o de Porto Alegre. Quando da descoberta do ouro e diamantes na região de Minas Gerais e da abertura do Caminho Novo, a importância do Rio de Janeiro cresceu de tal modo que, ao final do século XVIII, esse já era o maior porto do Brasil, interligando São Paulo, Minas Gerais, Mato Grosso e Goiás, entre outros locais (França, 2012; Marcondes, 2012; Russell-Wood, 2014). Nesse sentido, fica evidente que os portos do Recife e de Salvador foram importantes em nível nacional, notadamente nos séculos XVII e XVIII. Ainda assim, esses portos estavam em franca comunicação internacional no século XIX, inclusive com a importação de cachimbos, como ilustram manifestos de carga, veiculados em periódicos mercantis oitocentistas. Em consulta assistemática a alguns periódicos oitocentistas pernambucanos e baianos, foram observadas importações de cachimbos à cidade do Recife, provenientes de Londres, Hamburgo, Liverpool, Glasgow e de Havre, enquanto Salvador recebeu cachimbos de Hamburgo, Bordeaux, Havre e Southampton. Vários importadores/exportadores de mercadorias diversas revendiam seus itens para as vendas e lojas locais, de artigos em geral ou especializadas, sendo que havia vários comércios em operação concomitantemente. No que tange à distribuição de artigos associados ao consumo de tabaco, também apesar do caráter assistemático desta pesquisa, notou-se, de forma geral no Brasil, um movimento gradual em direção à especialização da venda de artigos do fumo, ao longo do século XIX (Hissa, 2018). É digno de nota o anúncio da Tabacaria em Recife, que figura um indígena norte-americano. Essa associação evoca o uso, na Europa e nos EUA, desde o século XVII, de estátuas em madeira desses indígenas, chegando a tamanho real, para sinalização de tabacarias ao público analfabeto (Figura 1). De todo modo, essa especialização não significa dizer que não havia, nas últimas décadas dos oitocentos, lojas de produtos genéricos comercializando cachimbos. Por fim, nota-se que as vendas de cachimbos no Recife oitocentista identificadas nesse levantamento assistemático em periódicos eram todas especializadas e localizadas na ilha Antônio Vaz.

\section{CACHIMBOS DE CAULIM DO RECIFE ANTIGO, PERNAMBUCO}

O primeiro povoado colonial no atual bairro do Recife Antigo remonta ao século XVI. Dito como 'cidade-etapa' na economia-mundo por Nascimento (2012), tornou-se o porto mais importante da capitania, escoando para a Europa a maior parte do açúcar então produzido; e, a partir de 1630, quando do incêndio em Olinda, passou a ser também a capital de Pernambuco (Vasconcelos; Sá, 2011). Essa ocupação, aldeia 'Povo', para os neerlandeses, atravessou grandes transformações urbanas no século seguinte, sobretudo sob domínio batavo. Mello, E. (2010 apud Hissa, 2018, p. 239) divide a presença neerlandesa no Nordeste em:

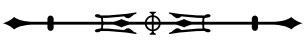


[...] uma fase inicial, de conquista holandesa e resistência luso-brasileira (1630-1637), um período de paz (1638-1645), e a fase final, de guerra e da restauração luso-brasileira (1645-1654). O período de paz, como aponta também Albuquerque (2009), coincide com a presença de João Maurício de Nassau-Siegen como governador do Brasil holandês (1637-1644).

O governo de Nassau teria promovido relativa prosperidade econômica, desenvolvimento urbano e uma convivência social parcialmente pacífica entre holandeses e luso-brasileiros (Albuquerque, 2009; Vainfas, 2016). Entre as transformações urbanas, é importante ressaltar os inúmeros aterramentos expandindo as terras firmes do istmo, que o conformava entre o mar e o rio salgado Beberibe; aplanamento de mangues; construção de pontes; drenagens de camboas; melhorias no porto; saneamento e arborização. Segundo Hissa (2018, p. 240),

Com o tempo, o Recife se estabeleceu como centro comercial e pólo urbano, e a ilha de Antônio Vaz como local de residência dos burgueses ricos e do Conde de Nassau. Enquanto isso, Olinda, a antiga capital, transformou-se em um símbolo para os luso-brasileiros.

Assim, o período da presença holandesa no país persistiu também na imaginação popular do início do século $X X$ nordestino como de "[...] opulência e maior adiantamento artístico, de um passado mais forte e substancial do que o presente de agruras e misérias." (Puntoni, 2012, p. 31).

Durante o período das investidas holandesas e dos 24 anos da própria ocupação batava em Pernambuco, que se sucedeu, grande número de pessoas veio para a colônia e aqui se instalou permanentemente. Integraramse, à população brasileira, vários soldados desertores ou já desligados formalmente da West-Indische Compagnie (WIC), cujo contingente era formado não somente de despossuídos e refugiados, mas também de pessoas com formação educacional básica e conhecedores de ofícios manuais (Mello, J., 1987; Stols, 2002; Miranda,

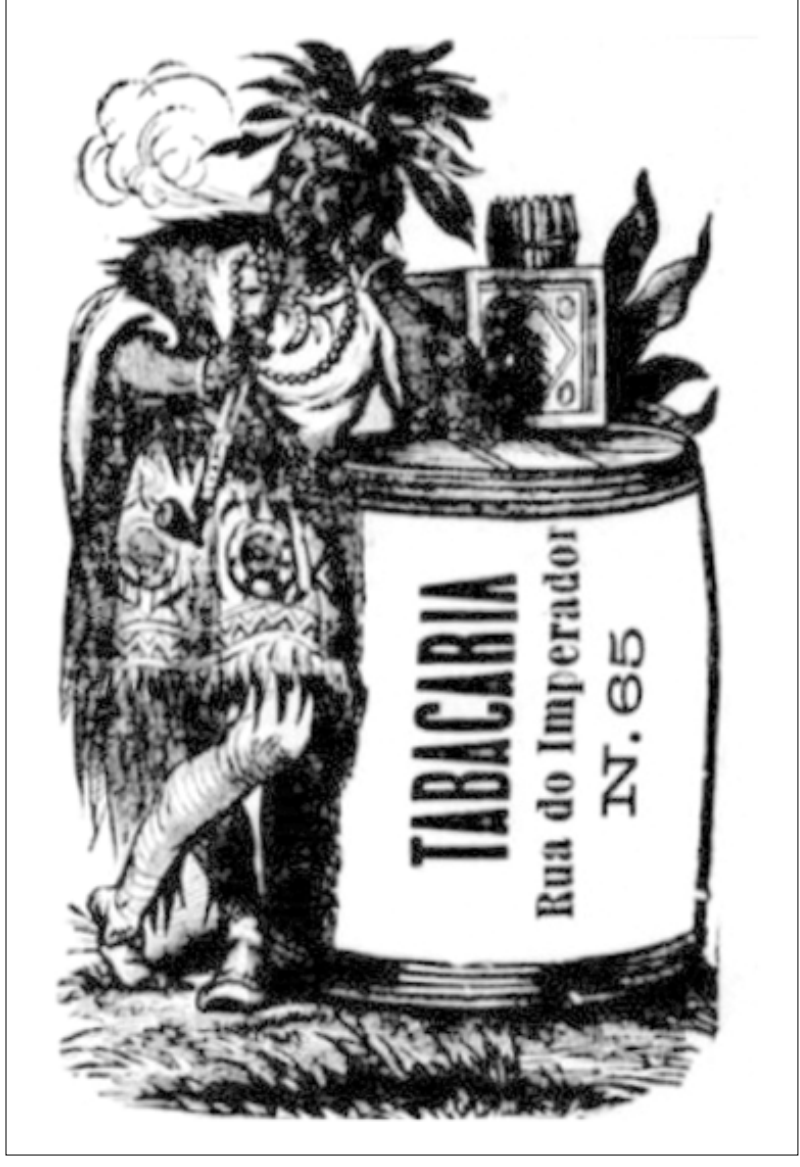

Figura 1. Anúncio da tabacaria situada à rua do Imperador, nº 65. Fonte: De festas (1874, p. 3).

2011, 2015). Essas pessoas trouxeram consigo hábitos e celebrações, animais (gatos, gansos, patos e porcos) e objetos de toda sorte, como tecidos e material construtivo; por outro lado, aprenderam muito com os portugueses sobre a vida na colônia e sobre as lavouras, como a do tabaco. Já esses, distintos dos primeiros também na sua simplicidade material doméstica, foram tidos por estrangeiros como preguiçosos, libertinos (tanto homens quanto mulheres), desonestos e cruéis. Segundo uma dessas visões, "[...] em 1666, o comandante francês, senhor de Mondevergue, registrara que os habitantes do Recife 'viviam com grande licença, gastavam o tempo dormindo e fumando' e eram muito pobres". (França, 2012, p. 258).

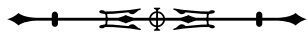


Trabalhos de escavação e de monitoramento arqueológicos na área do Recife Antigo, realizados entre 1999 e 2002 pelo Laboratório de Arqueologia, do Departamento de História, da Universidade Federal de Pernambuco (UFPE), sob a coordenação do Prof. Dr. Marcos Albuquerque, resultaram na descoberta de mais de 1.000 cachimbos de caulim, organizados pela equipe em uma coleção de referência, com 193 peças. O material exumado em análise proveio dos seguintes logradouros: praça Tiradentes, rua Domingos José Martins, avenidas Barbosa Lima, Rio Branco e Alfredo Lisboa, bem como as ruas do Bom Jesus, do Observatório e do Apolo (Figura 2). Considerando-se o histórico dos aterramentos voltados para a expansão dos limites do istmo do Recife (Menezes, 1988), nota-se que a maior parte desses logradouros foi construída por aterramentos realizados a partir dos séculos XVII e XVIII. Contudo, não foi identificada distinção significativa entre os cachimbos importados exumados desses prováveis aterros e os provenientes de provável deposição primária.

De forma geral, trata-se de um acervo de cachimbos de origem majoritariamente holandesa, típica do século XVII, a julgar pela decoração, pelas formas dos fornilhos identificados, pela localização das marcas de fabricante (predominantemente nas bases dos pedúnculos), pelos tipos das marcas de fabricante e pela identificação de fabricantes específicos (Figuras 3 e 4). De acordo com Hissa (2018, p. 251), "A sobreposição dos intervalos de produção das marcas identificadas sugere uma maior concentração e uso mais intenso de cachimbos de caulim na área estudada, especialmente entre as décadas de 1630 e 1660 [...]". Nota-se que a maior frequência de tipos é condizente com o período holandês da região (Figura 5). Concluiu-se também que essa coleção apresenta exemplares de boa qualidade e caros à sua época, contudo levemente menos rebuscados e custosos do que os encontrados no Forte Orange, Pernambuco, por exemplo'.

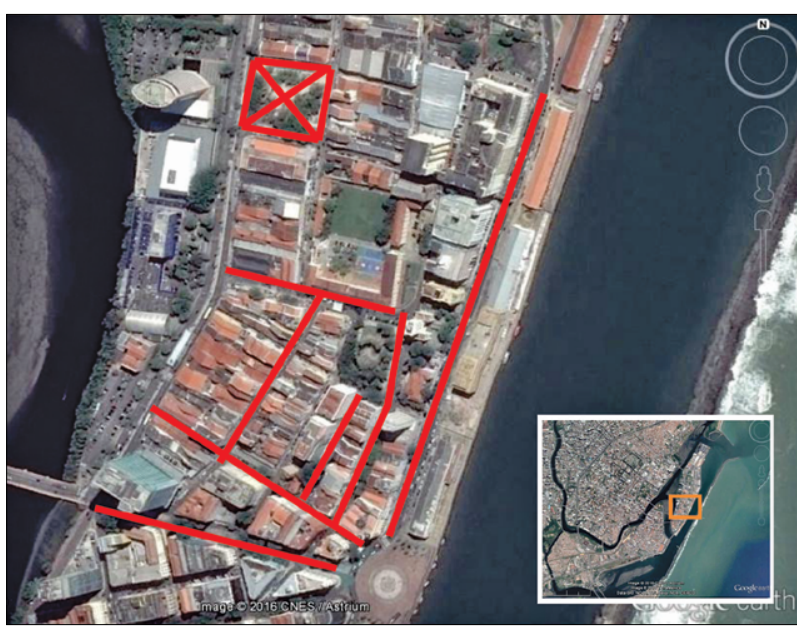

Figura 2. Logradouros onde foram identificados fragmentos de cachimbos de caulim: rua do Observatório, rua do Bom Jesus, avenida Alfredo Lisboa, rua Domingos José Martins, avenida Rio Branco, avenida Barbosa Lima, rua do Apolo e praça Tiradentes. Localização geral dos logradouros de onde o material em análise foi exumado. Recife Antigo, Pernambuco. Fonte: plataforma Google Earth (2018).

As decorações incisas, carimbadas e feitas com carretilha são mais frequentes do que as moldadas. São elas: serrilhado na borda do fornilho (presente em 54 fragmentos), bandados e vários estilos de decoração bordada (Hissa, 2018). Os moldados identificados apresentaram decoração barroca, rosa Tudor na lateral do fornilho e flores de lis em hastes (Figuras 6 e 7).

É importante ressaltar que 27 fragmentos-tipo foram identificados como barrocos, feitos na Holanda a partir do início da década de 1630. Entre os cachimbos produzidos no século XVII, estima-se que menos de 1\% era barroco, enquanto o barroco tipo 4 (Jonas), que foi fabricado durante um período mais longo em relação aos demais, representou em torno de $2 \%$ da produção. Para o fumante do século XVII, o cachimbo barroco é um item de luxo. Alguns eram adornados com uma decoração fina, a partir de moldes extremamente intrincados (Barroco tipo 1). 0 cachimbo meticulosamente decorado é seguido por uma

\footnotetext{
1 Uma descrição mais detalhada dessa coleção de cachimbos de caulim pode ser encontrada em Hissa (2018).
}

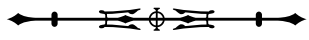


versão mais simples, que também chegou ao mercado no início da década de 1630 (Barroco tipo 2). O popular cachimbo do Jonas é do tipo barroco 4. Este cachimbo é muito mais comumente referenciado como cachimbo do Jonas, devido à história bíblica entre o profeta e a baleia (ou serpente). Os modelos mais antigos carregam a inscrição 'IONAS ANNO 1632', feitos em Hoorn, por vezes com um esmalte de chumbo verde, amarelado ou castanho. Foi muito adotado por marinheiros e soldados como símbolo, especialmente entre 1630-1680.

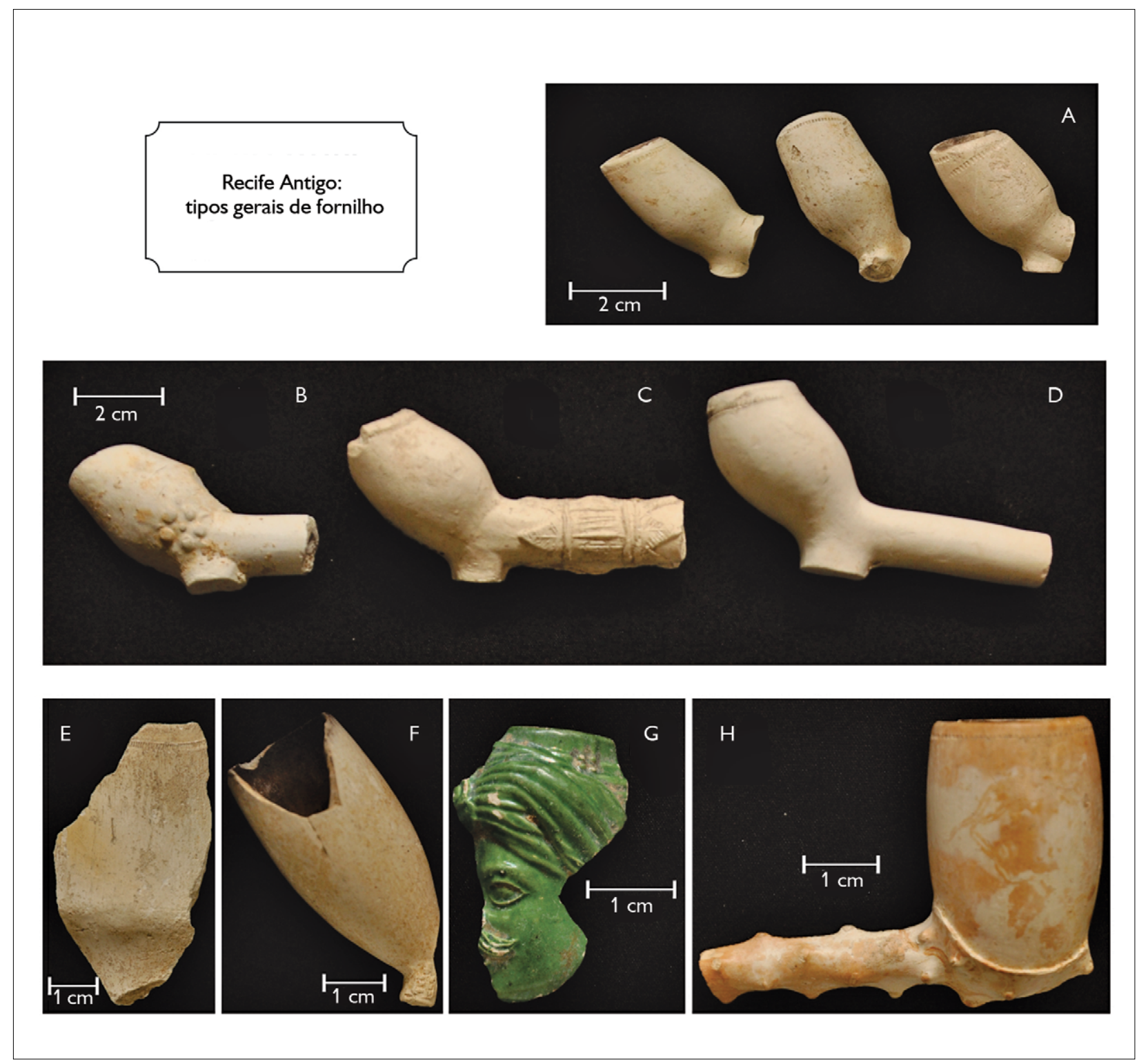

Figura 3. Tipos gerais de fornilhos: A) tipo bicônico; B) bicônico com flor moldada na lateral do fornilho; C) serrilhado na borda do fornilho bicônico e decoração moldada na haste; D) possivelmente inglês, com serrilhado na borda; E) bicônico grande, provavelmente holandês; F) ovoide, holandês, c. 1730-1850 (notar brasão de armas da cidade de Gouda, na lateral do pedúnculo); G) oriundo do século XIX, provavelmente francês; H) oriundo do século XIX (tipo reto), holandês, provavelmente Gouda, c. 1850-1900 (marca de fabricante no cotovelo 'A leiteira'). Recife Antigo, Pernambuco. Fonte: Hissa (2018, p. 245).

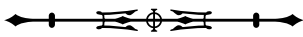




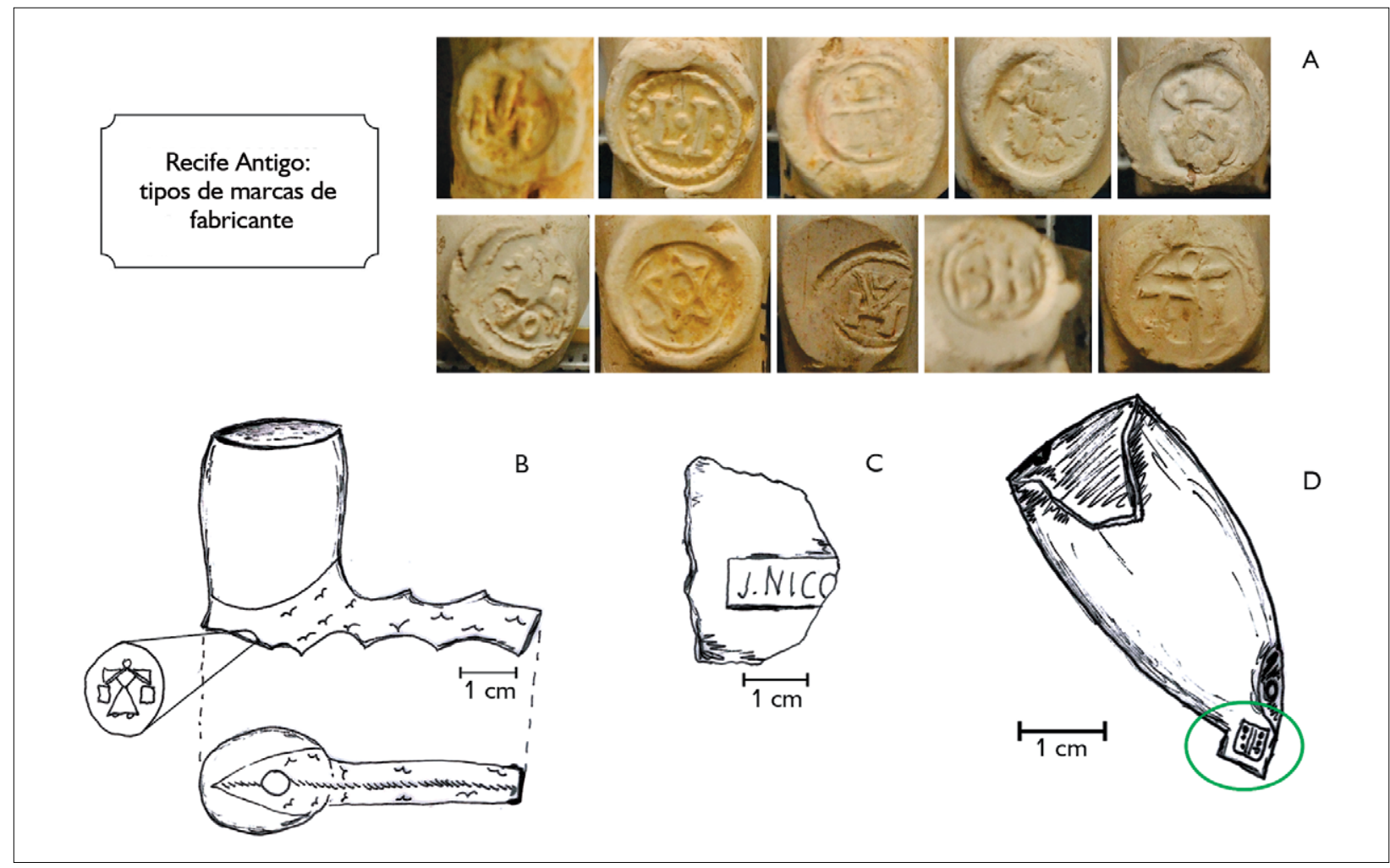

Figura 4. Tipos de marcas de fabricante: A) fotos de vários exemplares de marcas de fabricante, localizadas no pedúnculo; B) marca 'A leiteira', no fornilho tipo reto, 1850-1900, Gouda, Holanda; C) 'J. NICOT', provavelmente de Ardenne, Bélgica, em meados do século XIX; D) na lateral do pedúnculo, brasão de armas de Gouda no fornilho ovoide, c. 1730-1850. Recife Antigo, Pernambuco. Fonte: Hissa (2018, p. 250).

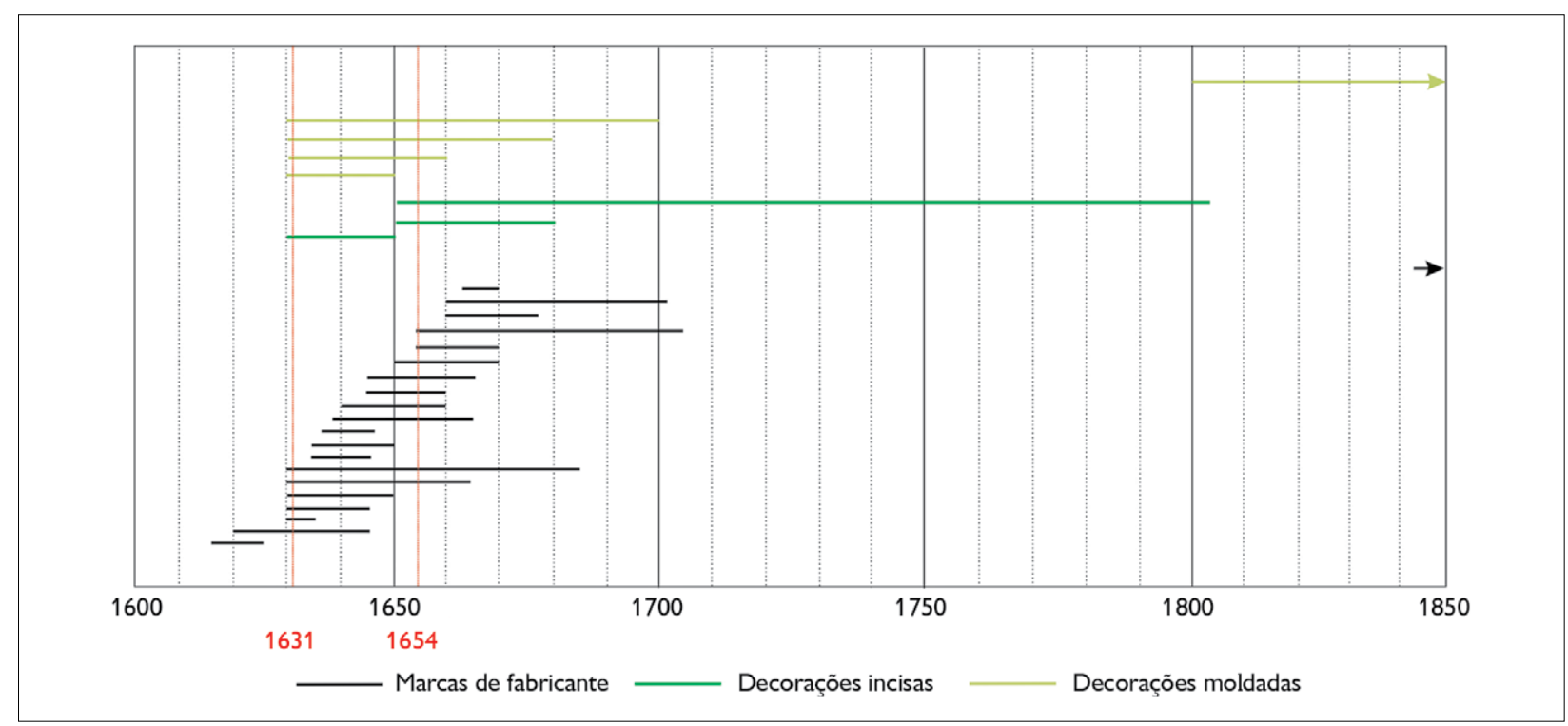

Figura 5. Gráfico do intervalo cronológico, observando-se os tipos decorativos identificados e as marcas de fabricante. As linhas verticais vermelhas apontam o período holandês da região. Recife Antigo, Pernambuco. Fonte: Hissa (2018, p. 252).

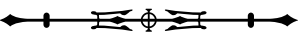




\section{Recife Antigo: tipos gerais de decoração moldada}
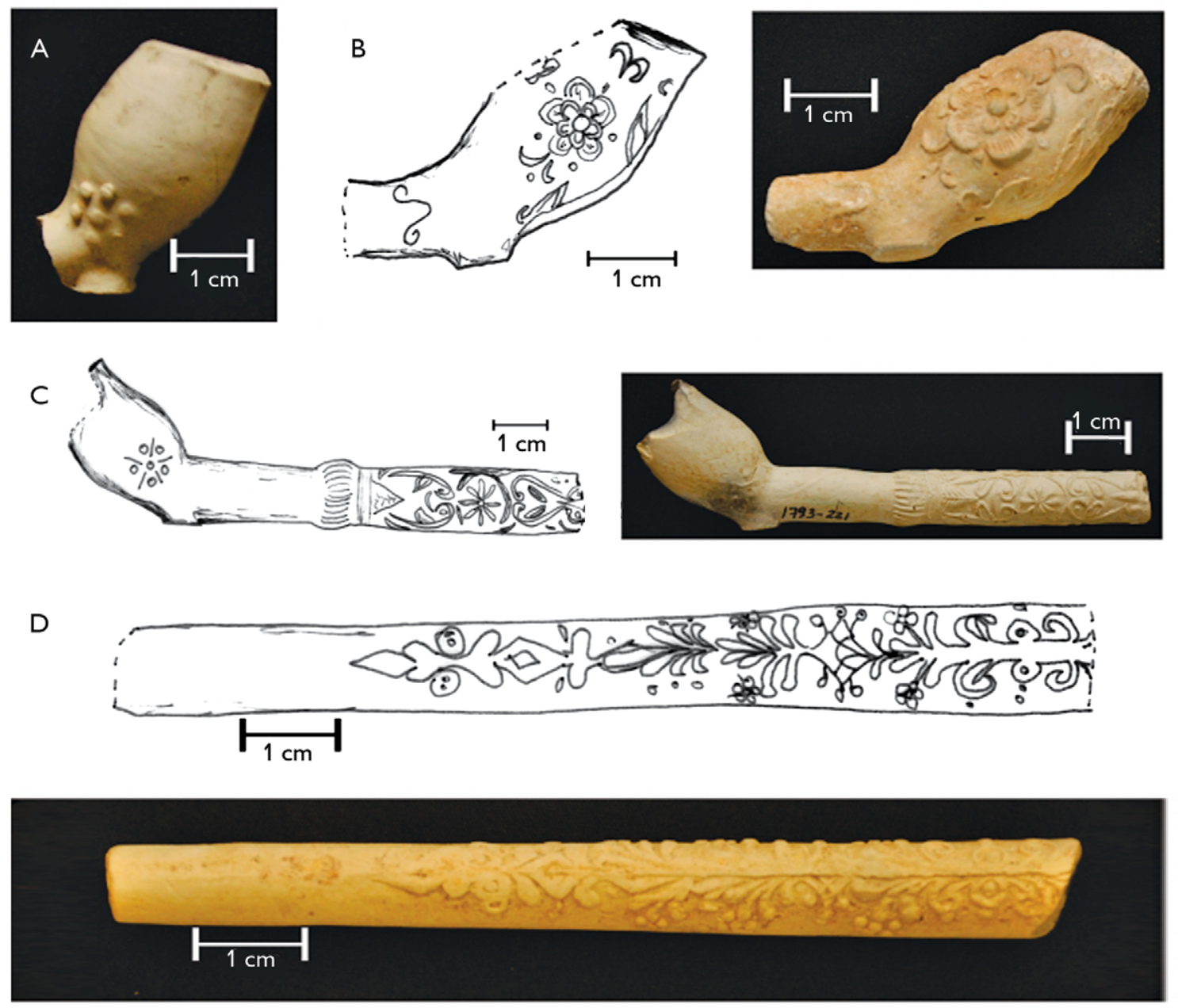

\section{E}

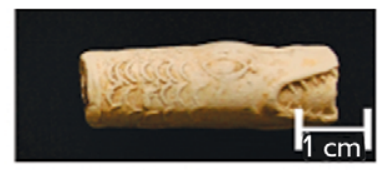

F

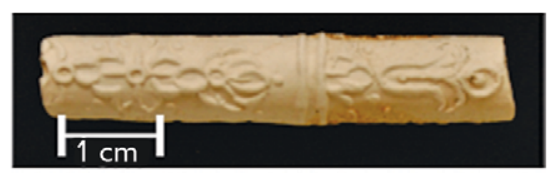

G

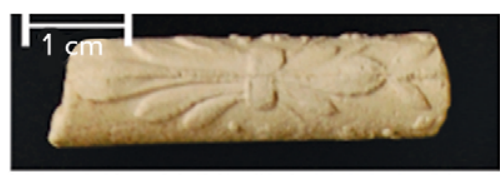

Figura 6. Tipos gerais de decoração moldada: A) rosa Tudor estilizada, na lateral do fornilho bicônico; B) florais no fornilho bicônico; C) rosa Tudor estilizada, na lateral do fornilho bicônico e haste barroca; D) haste barroca; E) zoomorfo na haste; F) floral na haste; G) floral na haste. Recife Antigo, Pernambuco. Fonte: Hissa (2018, p. 248).

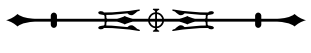




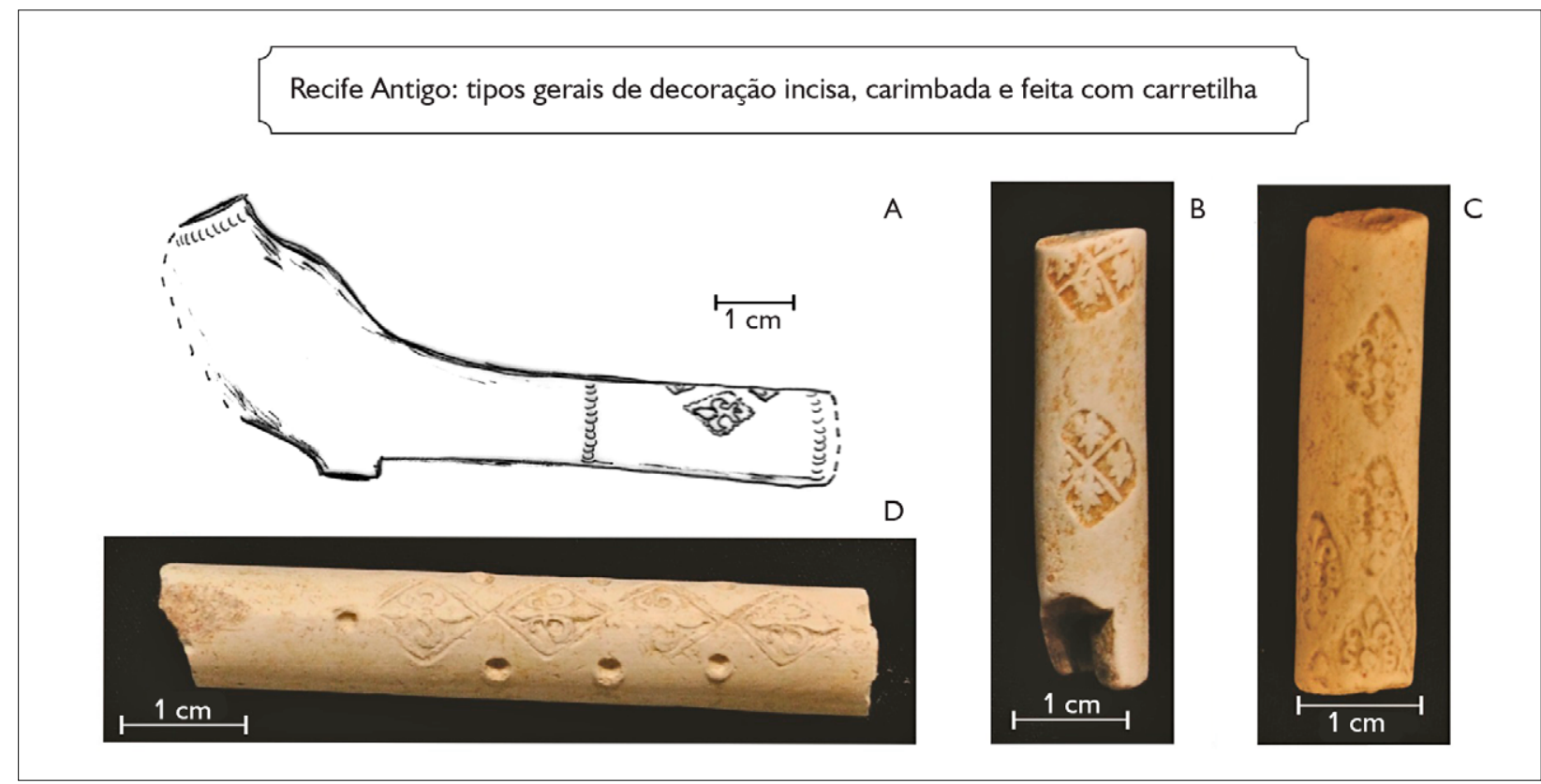

Figura 7. Tipos gerais de decoração incisa, carimbada e feitas com carretilha: A) serrilhado na borda do fornilho bicônico, bandas serrilhadas na haste e bordado (cartuchos losangulares circunscrevendo flores de lis); B e C) hastes com decoração bordada: cartuchos losangulares; D) haste bordada (cartuchos losangulares circunscrevendo flores de lis e pontos incisos feitos na pasta fresca). Recife Antigo, Pernambuco. Fonte: Hissa (2018, p. 247).

\section{CACHIMBOS DE CAULIM DA SÉ PRIMACIAL DE SALVADOR, BAHIA}

São Salvador da Bahia de Todos os Santos foi implantada sobre uma escarpa de falha, bem posicionada e protegida do ponto de vista tático. A divisão da cidade em função do relevo expressava também separações sociais e ocupacionais de seus habitantes: na cidade baixa, as atividades comerciais e portuárias, cais, alfândega, armazéns; na cidade alta, edificações religiosas, prédios administrativos e residências abastadas. A Sé Primacial foi construída na parte alta em meados do século XVI. Anos depois, essa edificação foi tomada durante a curta investida holandesa à cidade, entre 1624-1625, e utilizada pelos batavos como posto de defesa, armazém e dormitório dos militares (Peres, 1974). Contudo, o salteamento da cidade pelos neerlandeses foi malsucedido, e logo a Sé e a urbe voltaram para a normalidade luso-brasileira.
A parte alta da cidade sofreu intensas alterações durante o século XIX, com obras de aterramento que possibilitaram ampliar sua ocupação. A Sé, desde o século XVIII, já perdia influência e, no século seguinte, a freguesia como um todo foi perdendo suas características elitistas. A construção da praça Dona Isabel à frente da Sé, em 1865 (renovada em 1883), e outros eventos implicaram o nivelamento do terreno com material de aterro, o que pode ser visto como uma tentativa de revitalização da área. De todo modo, em 1933, a antiga catedral, já bastante descaracterizada, foi demolida pela prefeitura da cidade, para abrir espaço ao trajeto de um moderno bonde. Assim, "[...] o monstro de pedra e cal voltou a dormir tranquilo no enorme espaço que ocupa no eixo da R. da Misericórdia."2 (Santos, 1933; Peres, 1974; Etchevarne, 2001; Liryo, 2003; Rocha, 2007; Carmo; Bastos, 2010; Najjar, 2010; Costa, 2015).

2 O jornal A Tarde, Bahia, de 10/12/1929, menciona pejorativamente a Sé Primacial do Brasil, Salvador, Bahia, como um 'monstro de pedra e cal', após sua demolição (Peres, 1974).

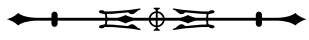


Os cachimbos de caulim aqui em análise provieram de escavações arqueológicas realizadas na Sé e imediações, coordenadas pelo Prof. Dr. Carlos Etchevarne (Universidade Federal da Bahia - UFBA), entre 1998-2001, e associadas às comemorações dos 450 anos da cidade. Muitas pesquisas acadêmicas posteriores ao trabalho de campo foram publicadas sobre vários elementos do sítio e o acervo gerado (Costa, 2005, 2015; Etchevarne, 2006; Tavares, 2006; Mendonça; Etchevarne, 2007; Etchevarne et al., 2011; Mendonça, 2012; Barros, E., 2010; Barros, M., 2013).

Somam 230 peças $^{3}$, entre as quais a grande maioria era composta somente por hastes, com somente 13 fornilhos (Figura 8). A maior parte dessa coleção (à qual se excetuam somente dois fragmentos vindos dos setores $A$ e B) proveio da área localizada em frente a Sé, denominada de Setor $F$, o qual é composto por quatro pacotes estratigráficos (Figura 9). Considerando-se o potencial cronológico dos diâmetros dos furos de haste, formas dos fornilhos e marcas de fabricante, observou-se a datação dos cachimbos de cada pacote (Hissa, 2018). O pacote 1, mais raso e mais recente, apresentou cachimbos de caulim produzidos entre os séculos XVII e XVIII, o qual teria sido um nivelamento do terreno para construção da praça Dona Isabel, já no século XIX, utilizando-se, então, de sedimentos que continham artefatos anteriores. Abaixo desse, o pacote 2 incluiu poucos cachimbos de caulim, com intervalo total de produção dos séculos XVII ao XIX. O pacote 3, que continha porções originais do terreno do adro da igreja, apresentou apenas dois desses fragmentos. $O$ pacote 4 era um aterro de cerca de $4 \mathrm{~m}$ de profundidade, seccionando os demais estratos, com cachimbos de caulim associados principalmente ao século XVII. Notou-se que há 23 fragmentos do setor F, especialmente dos pacotes 1 e 4 , erodidos ou descamados por erosão, alguns provavelmente por água, a julgar pelo arredondamento das arestas. Tais fragmentos possibilitam aventar que esses aterros poderão ter compilado sedimentos originalmente depositados na parte baixa da cidade. A despeito do gigantesco empreendimento que isso significaria, a saber, a movimentação de depósitos sedimentares da cidade baixa à parte alta de Salvador, lembra-se que o trabalho forçado instituído nas lavouras e

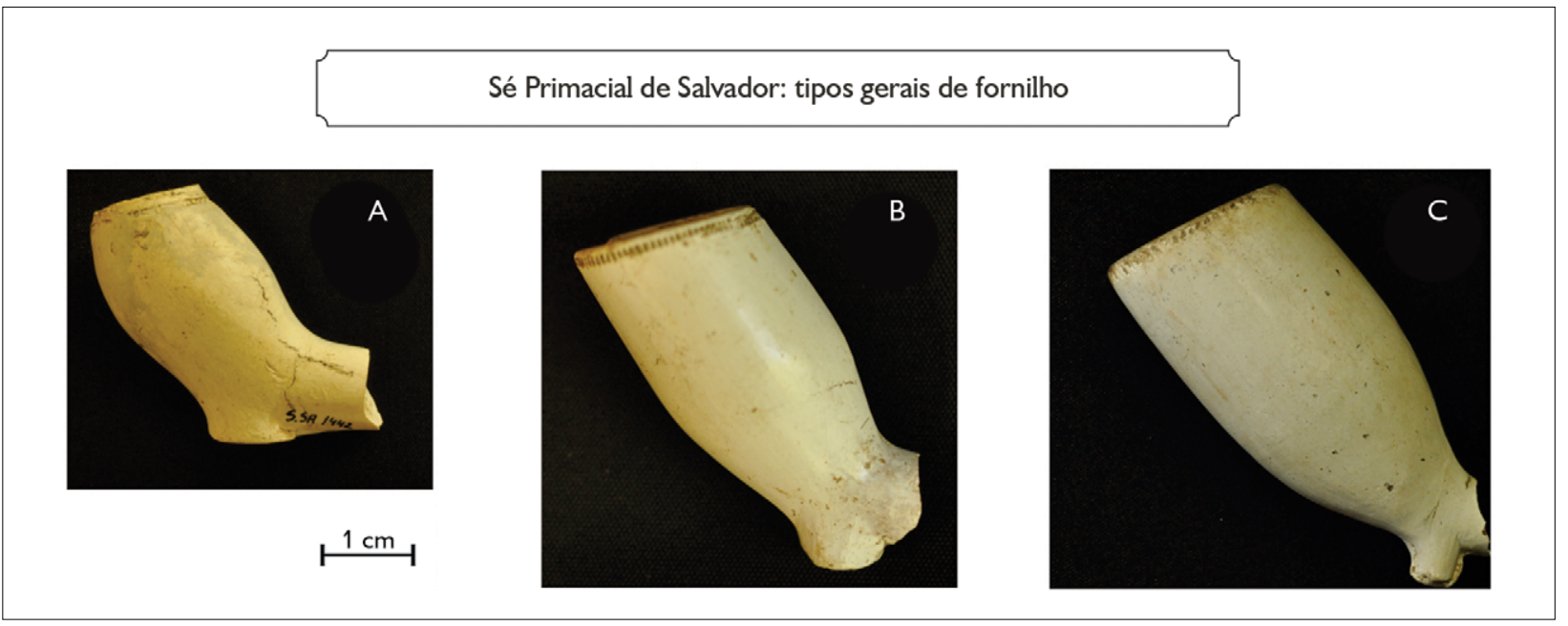

Figura 8. Tipos gerais de fornilho: A) bicônico, possivelmente inglês; B e C) em formato de funil. Sé Primacial de Salvador, Bahia. Fonte: Hissa (2018, p. 262).

3 Ressalte-se novamente que os cachimbos do Recife Antigo aqui analisados se referem a uma seleção (a coleção-tipo), enquanto a coleção completa de fragmentos de cachimbos de caulim escavados na Sé foi estudada.

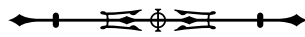




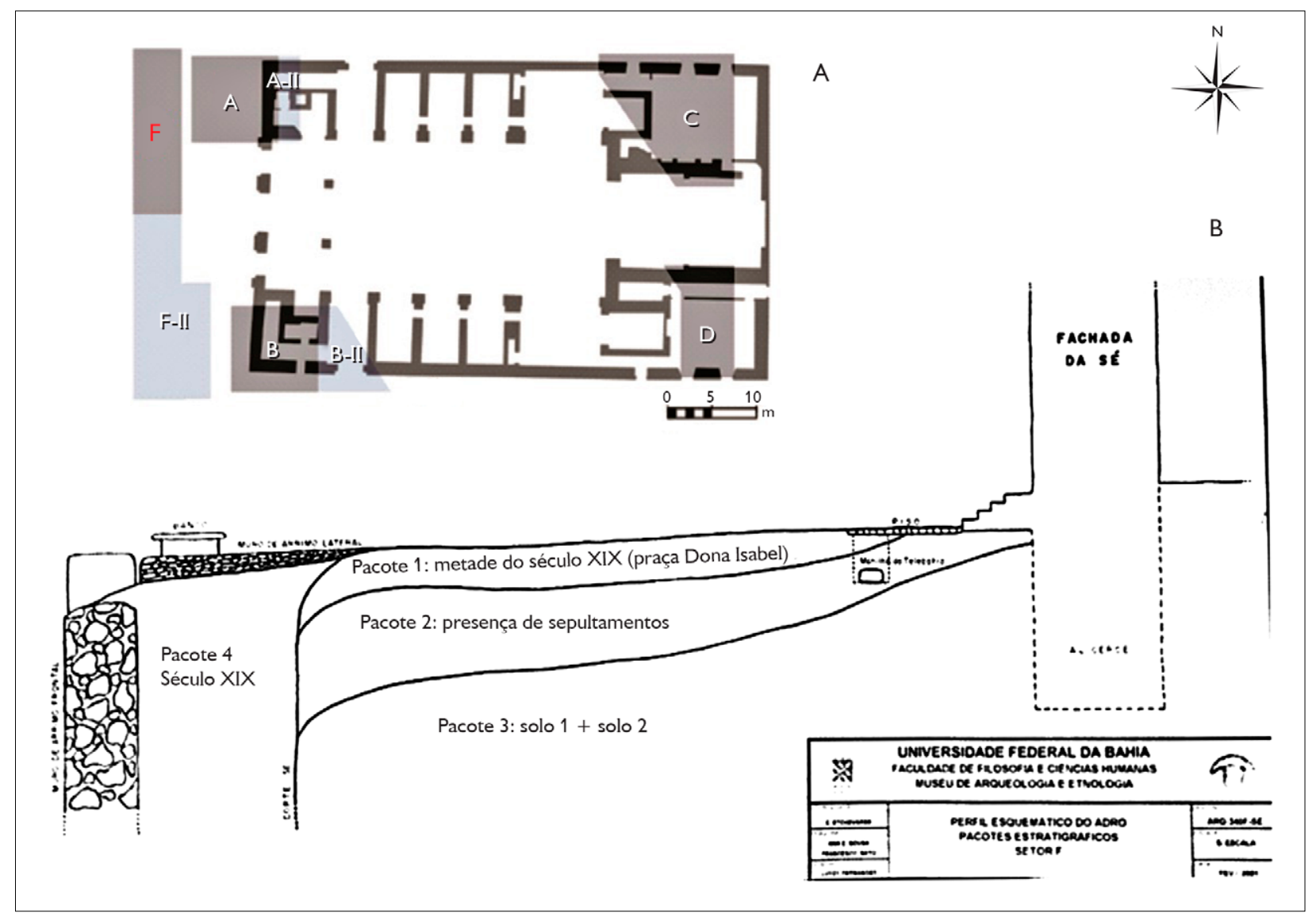

Figura 9. Planta baixa e perfil estratigráfico do sítio: A) distribuição dos setores de escavação sobre a planta da Sé. Notar o setor F, de onde saiu a maior parte dos fragmentos de cachimbos de caulim. Ele corresponde ao adro da igreja, estando, portanto, defronte aos setores A e B; B) disposição geral dos pacotes estratigráficos do adro da Sé. Fonte: Etchevarne (2001). Sé Primacial de Salvador, Bahia. A planta em A foi elaborada por Gentil Marinho, com edições de Carlos Costa. Fonte: Hissa (2018, p. 269-271).

na mineração em tantos lugares da colônia não estaria tão distante desse. Ainda, observando-se a relação entre as datações atribuídas a cada fragmento de cachimbo de caulim e suas profundidades no pacote 4, não foi observado padrão algum, regular ou semirregular, o que sugere a formação do aterro a partir da deposição de material já bastante perturbado, seja ela gradual ou em um único evento.

Foram identificadas marcas de fabricante na haste, no fornilho e no pedúnculo (Figura 10). Tal como feito para a coleção do Recife Antigo, a partir de dados cronológicos associados à forma do fornilho, marcas de fabricante e tipos decorativos, a produção dos cachimbos identificados indica o intervalo entre 1600 e 1740. Nota-se que o período avança para o século XVIII, ultrapassando facilmente o breve período holandês de menos de um ano de ocupação da cidade ou mesmo o da ocupação de Pernambuco (Figura 11)4.

De modo geral, os cachimbos encontrados no aterro em frente à Sé apresentam tipos decorativos mais simples e mais baratos do que aqueles exumados do Recife Antigo. As decorações moldadas, em especial as barrocas, bastante caras no século XVII, não estão presentes.

\footnotetext{
4 Para informações com maior detalhamento acerca das descrições, identificações e datações do material, ver Hissa (2018).
}

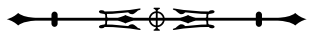


Ainda, em várias peças há alguns indícios associados à má qualidade de produção ou com acabamento simples, como inclusões na pasta, costuras de molde pouco arrematadas, esmagamento da haste, furo da haste mal centralizado e bandas anelares e serrilhados sobrepostos na borda do fornilho ou haste. É como se houvesse uma diminuição progressiva do rebuscamento decorativo e dos preços, à medida que a presença militar batava se rarefaz, no tempo e no espaço. Por outro lado, há também decorações elaboradas, como o bordado, e indícios de bom acabamento de superfície, como polimento e pontos moldados na lateral do pedúnculo ${ }^{5}$. Assim, fica evidente que se trata de uma coleção formada por exemplares que apresentam, em geral, qualidade e custo de medianos a baixos, considerando-se as várias nuances do mercado de cachimbos holandeses (Figura 12).

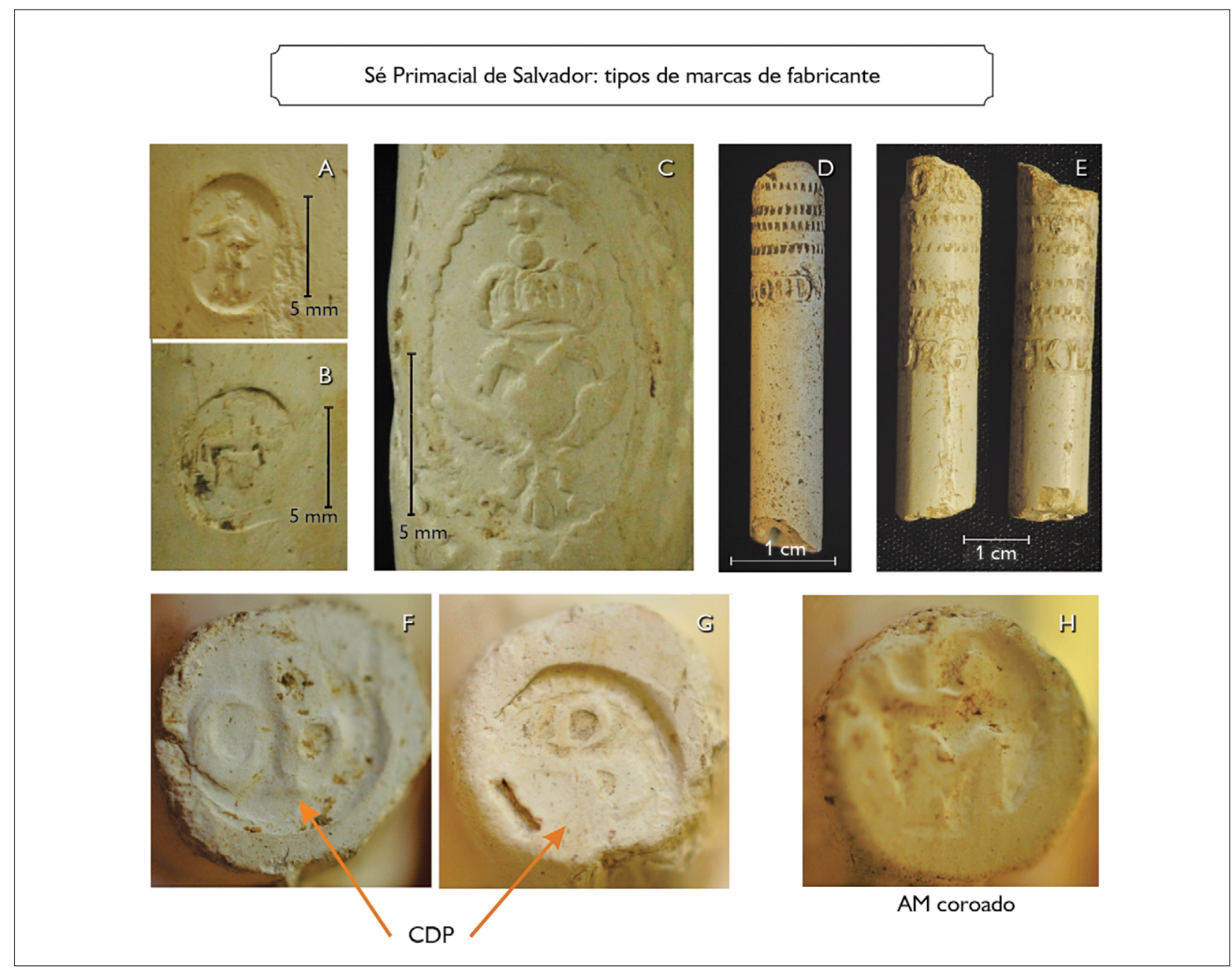

Figura 10. Tipos de marcas de fabricante: A) Davi e Golias, Gouda, século XIX; B) não identificado; C) águia bicéfala, Gouda, fins do século XVII-início do XVIII; D) inscrição 'INGOUDA', 1730-1790; E) inscrição 'EORS'? e'*BURGKL*', Gouda, meados do século XVIII; F e G) CDP; H) AM coroado. Sé Primacial de Salvador, Bahia. Fonte: Hissa (2018, p. 268).

5 O ponto moldado na lateral do pedúnculo pode ser um indicador de melhor qualidade, sendo, entretanto, pouco estudado (Dallal, 1990). A coleção da Sé conta com dois fornilhos com círculo em alto relevo moldado na lateral próxima ao pedúnculo.

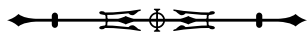




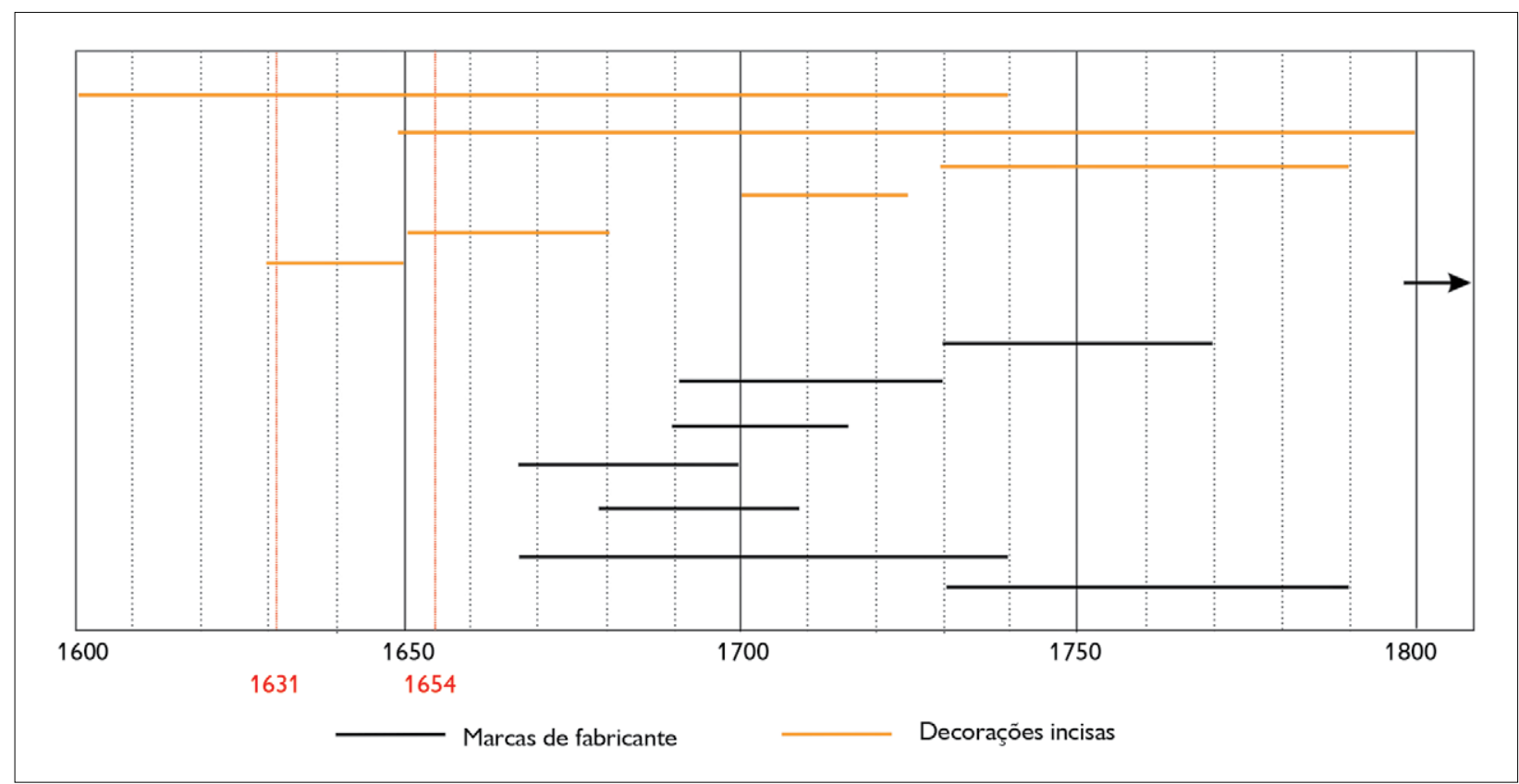

Figura 11. Gráfico do intervalo cronológico dos tipos decorativos identificados. As linhas verticais vermelhas apontam o período holandês da região. Sé Primacial de Salvador, Bahia. Fonte: Hissa (2018, p. 277).

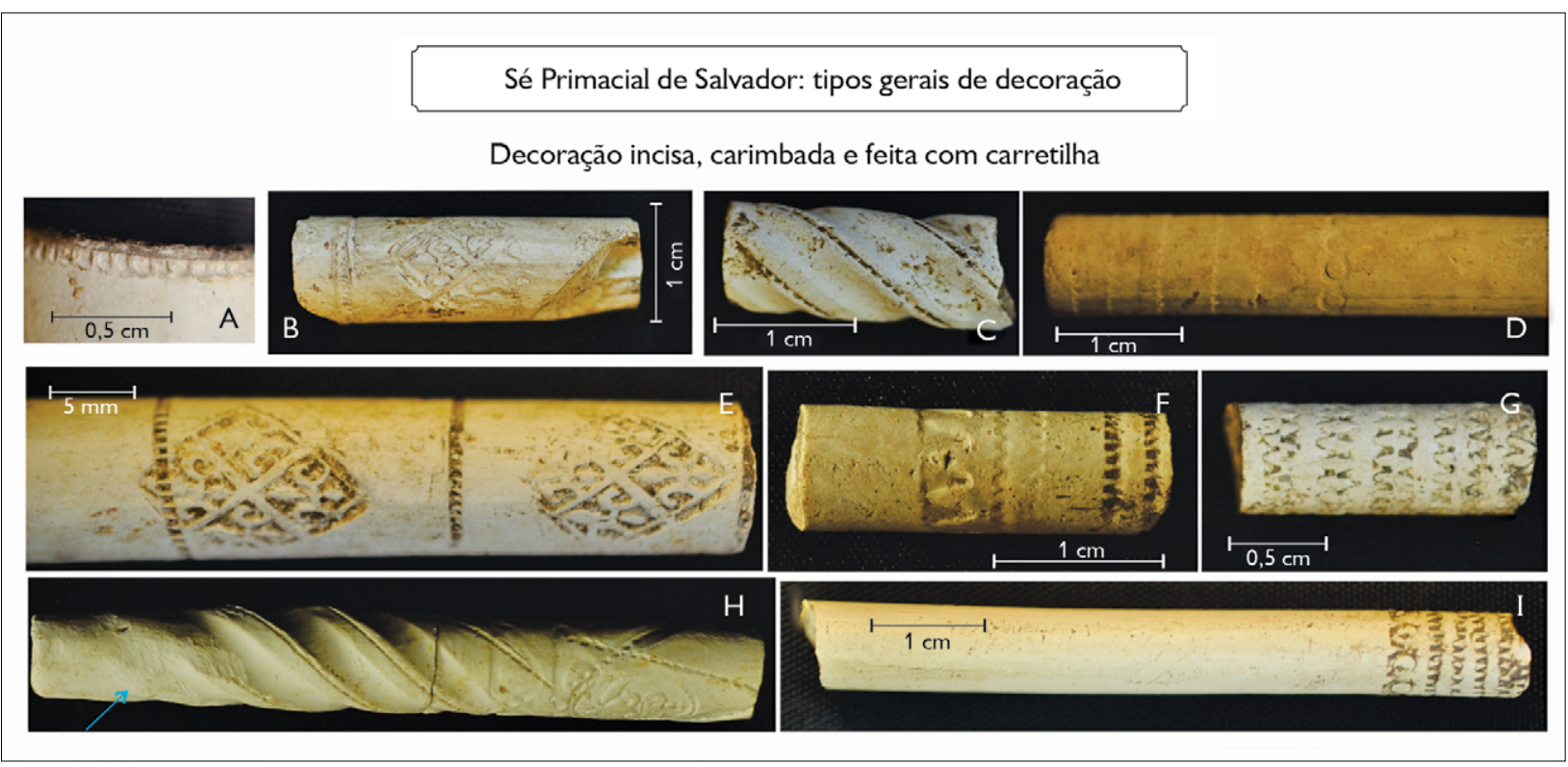

Figura 12. Tipos gerais de decoração. Decoração incisa, carimbada e feita com carretilha: A) serrilhado na borda do fornilho; B) à direita, torção moldada com banda anelar (serrilhado), $1^{\circ}$ quartel do século XVIII; C) torção moldada com banda anelar (serrilhado), $1^{\circ}$ quartel do século XVIII; D) banda anelar com serrilhados e perolados, $1^{\text {a }}$ metade do século XVIII; E) conjunto de flores de lis e banda anelar (serrilhado); F) bandas anelares em serrilhado e zigue-zagueado; G) bandas anelares em zigue-zagueado, $1^{a}$ metade do século XVIII; H) torção moldada e banda anelar (serrilhado), decoração típica do $1^{\circ}$ quartel do século XVIII (notar marca de fabricante carimbada - águia bicéfala coroada, a ser discutida adiante - e as marcas de reciclagem - seta azul); I) bandas anelares, em círculos e serrilhado, $1^{a}$ metade do século XVIII. Sé Primacial de Salvador, Bahia. Fonte: Hissa (2018, p. 263).

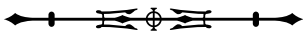




\section{ARREMATES}

Após essa visão geral de duas coleções urbanas de cachimbos de caulim no Nordeste brasileiro, é necessário oferecer alguns arremates que possibilitem conectar os elementos descritos, traçar possíveis significados e, até mesmo, indicar questões para discussões futuras. Ressalto, ainda, a minha ciência de que as amarrações aqui esboçadas se baseiam apenas em pequenas amostras, sendo insensato inferir de forma absoluta os hábitos das cidades do Recife e de Salvador como um todo. Mas arrisquemos.

Observamos que os cachimbos de caulim do Recife Antigo são holandeses em sua esmagadora maioria e que sua cronologia é majoritariamente condizente com a ocupação de Pernambuco no século XVII. Mesmo sendo o cachimbo neerlandês o objeto do fumo mais popular nos séculos XVII e XVIII na Europa, inclusive em Portugal, ele não perdura muito após a retirada batava. Estimamos também que os depósitos dos quais eles provieram referem-se tanto a material de aterro quanto a provável descarte primário. Disso decorre que seus fumantes estariam principalmente circunscritos cronologicamente à ocupação neerlandesa da cidade, e que ao menos parte dos cachimbos referentes ao século XVII aqui analisados está relacionada a um fumo in loco, no istmo do Recife. Esse cenário permite quatro interpretações, possivelmente concomitantes. Em uma primeira, aqueles homens simples que fumavam o cachimbo holandês eram luso-brasileiros que aparentemente não adotaram o cachimbo de caulim holandês, após a expulsão do batavo. Em uma segunda interpretação, os fumantes luso-brasileiros desses cachimbos passaram a utilizar outro local da cidade. Em uma terceira, os fumantes que deixaram aqueles cachimbos neerlandeses do século XVII eram os próprios ocupantes e se foram com a retirada holandesa. No quarto cenário, esses fumantes do século XVII eram marinheiros e/ou comerciantes estrangeiros de várias outras nacionalidades, os quais também partiram naquele momento. Considerando-se que o intervalo de produção de grande parte desses cachimbos coincide com a ocupação batava, o mais provável é que seus usuários eram os holandeses. E, de fato, ainda hoje, os cachimbos brancos são comumente referidos no Recife como 'dos' batavos.

Por outro lado, nota-se que alguns dos tipos decorativos moldados mais caros do século XVII não foram encontrados no Recife Antigo, como estão no Forte Orange, descritos em Hissa (2018). Mesmo a amostra estudada sendo pequena e tipológica, é possível inferir que se trata de cachimbos levemente mais simples que os escavados na dita fortificação. Lembra-se que a ilha de Antônio Vaz foi referia como local de residência de holandeses burgueses ricos, enquanto o Recife Antigo, local de comércio e de gentes simples. Possivelmente, essa diferença estética e de preço observável entre os cachimbos do forte, onde havia oficiais de primeira linha, e os do Recife, poderá ser explicada pelo fato de residirem e circularem pessoas de menos posses nessa parte da cidade:

\begin{abstract}
Resta saber se a ilha de Antônio Vaz apresenta cachimbos barrocos e demais cachimbos holandeses refinados. Interessante também será observar quais objetos do fumo guarda Olinda, enquanto localidade que agrupava a elite dos grandes fazendeiros lusobrasileiros. (Hissa, 2018, p. 257).
\end{abstract}

Já os cachimbos exumados dos aterros à frente da Sé de Salvador não se referem a descarte primário após um fumo in loco, nem da ocupação holandesa da igreja entre 1624-1625, nem do seu uso como posto defensivo espanhol e português em 1638, mas a refugo deslocado (South, 1977). São também cachimbos de qualidade e com preços medianos a baixos, dentro do espectro de cachimbos holandeses. É possível que tenham sido utilizados pela própria elite da parte alta da cidade, de modo que cachimbos considerados na Europa de pouca notabilidade e status tenham sido consumidos aqui sob outra valoração. Contudo, é curioso que os cachimbos de caulim barrocos estejam ausentes logo na cidade de Salvador, onde a arquitetura religiosa em voga ostenta intrincados elementos desse estilo. Além disso, tendo em vista sua relativa simplicidade decorativa, imagina-se também a possibilidade de que tenham sido utilizados por 
marinheiros, estivadores, comerciantes, viajantes, entre outros, que teriam mais fácil acesso ao objeto importado em tempos de pacto colonial entre Brasil e Portugal. A isso se somam os mencionados fragmentos erodidos pela ação da água e a possibilidade de que os aterros e os cachimbos neles contidos possam ter vindo, ao menos parcialmente, da parte baixa de Salvador, onde tais pessoas habitavam e a percorriam mais frequentemente. De todo modo, a coleção da Sé é claramente composta de cachimbos fumados durante e principalmente depois da presença holandesa em Salvador e no Nordeste como um todo. Ainda que produzidos na Holanda, não se referem ao período da ocupação holandesa do Nordeste brasileiro e ao uso militar batavo. Enquanto a ocupação holandesa em Pernambuco foi longa e com marcas profundas, que persistem até hoje, a de Salvador foi curta e improfícua. E se no Recife os cachimbos setecentistas feitos na Holanda são 'de holandês', em Salvador, seriam somente holandeses.

\section{CONSIDERAÇÕES FINAIS}

Como visto, o estudo dos cachimbos de caulim, a partir da identificação das marcas de fabricante, da morfologia do fornilho e da decoração geral da peça, oferece grande potencial para datação de sítios e estratos arqueológicos, mesmo os que foram revolvidos ou deslocados. O local de feitura desses produtos também pode ser aferido por meio dos mesmos atributos anteriormente citados. Assim, as discussões que podem ser viabilizadas a partir da identificação da proveniência e do intervalo de produção são várias. A circulação de produtos industrializados no mercado fumageiro global é a que se coloca já de início. É necessário discutir a maneira pela qual, do 'como' em sentido amplo, tais commodities chegaram ao território hoje brasileiro; quem os trouxe e em que contexto. Além disso, importa discutir elementos sociais e culturais que $\mathrm{O}$ envolvem, mesmo esse objeto sendo industrializado, como quais teriam sido as categorias sociais e/ou ocupacionais que (mais) adotaram esses cachimbos importados ou onde, na cidade, eles o teriam (mais) utilizado, podendo afastar-se da busca de padrões e chegar a questões cada vez mais particulares ou eventuais.

Assim, consciente de serem apenas proposições, essas são aqui sugeridas a partir de dados históricos, localização das peças arqueológicas nas cidades e elementos formais, cronológicos e de custo inferido dessas peças. A compreensão dos fumadores dos cachimbos encontrados à frente da Sé e nas ruas do Recife Antigo vai aproximadamente no mesmo sentido, a de vinculá-los a categorias sociais e ocupações de ofícios associados ao mar. Os do Recife, de fato, poderão estar associados aos batavos em trânsito na urbe, soldados e oficiais de baixas a médias patentes, mesmo que não exclusivamente. Outros marinheiros, como também comerciantes, em circulação na cidade poderão tê-los usado e descartado. Já os da Sé, apesar de serem produtos holandeses, pela sua cronologia já não podem ser diretamente associados aos batavos militares e ocupantes. De atribuição mais complexa, sobre os modestos cachimbos encontrados, pensa-se tentativamente nos homens do mar e comerciantes, novamente, mas deixando em aberta a possibilidade do seu uso pelas elites, sob nova valoração.

\section{AGRADECIMENTOS}

Agradeço à profa. Dra. Tania Andrade Lima (Museu Nacional da Universidade Federal do Rio de Janeiro); ao prof. Dr. Marcos Albuquerque (Universidade Federal de Pernambuco) e à equipe do Laboratório de Arqueologia; ao prof. Dr. Carlos Etchevarne (Universidade Federal da Bahia); ao prof. Dr. Luydy Fernandes (Universidade Federal do Recôncavo da Bahia) e ao Museu de Arqueologia e Etnologia da Universidade Federal da Bahia; ao prof. Dr. Bruno Miranda (Universidade Federal Rural de Pernambuco); à profa ${ }^{\mathrm{D}} \mathrm{r}^{\mathrm{a}}$. Hannedea Van Nederveen Meerkerk (Monuments of the Dutch West India Company Foundation); ao prof. Dr. David Higgins (Universidade de Liverpool); a Jan Van Oostveen e a Igor Rodrigues, que, de formas distintas, deram apoio a esta pesquisa. 


\section{REFERÊNCIAS}

ALBUQUERQUE, Marcos. Arqueologia do Forte Orange. DaCultura, Brasília, ano 9, n. 15, p. 37-47, 2009.

BARROS, Evânia Lima. Cachimbos da Sé de Salvador. 2010. Trabalho de Conclusão de Curso (Bacharelado em Museologia) - Universidade do Recôncavo da Bahia, Cachoeira, 2010.

BARROS, Maria de Fátima Pombo. Cachimbos de caulim do sítio arqueológico Praça da Sé. 2013. Trabalho de Conclusão de Curso (Bacharelado em Museologia) - Universidade do Recôncavo da Bahia, Cachoeira, 2013.

CARMO, Alane Fraga do; BASTOS, Débora Bacelar. Pesquisa histórica e arqueologia. In: NAJJAR, Rosana (org.). Arqueologia do Pelourinho. Brasília: Programa Monumenta: IPHAN, 2010. p. 33-55.

COSTA, Carlos Alberto Santos. A Sé primacial do Brasil: uma perspectiva histórico-arqueológica. Resgate da Memória, Salvador, ano 2, n. 4, p. 3-25, 2015.

COSTA, Carlos Alberto Santos. Materiais construtivos do sítio da primeira catedral do Brasil: modelos de estudo para telhas, tijolos, cravos e azulejos aplicados aos materiais do sítio da antiga igreja da Sé, Salvador, Bahia. Clio Arqueológica, Pernambuco, v. 2, n. 19, p. 43-78, 2005.

DALLAL, Diane. Apendix F: pipe analysis. [S.I.], 1990. Hanover Square Report. Disponível em: http://s-media.nyc.gov/agencies/pc/ arch reports/122.pdf. Acesso em: 11 mar. 2016.

DE FESTAS. Jornal do Recife, Recife, ano 17, n. 267, p. 3, 28 nov. 1874. Disponível em: http://memoria.bn.br/pdf/705110/ per705110_1874_00267.pdf. Acesso em: 3 maio 2019.

ETCHEVARNE, Carlos; COSTA, Carlos; TAVARES, Aurea. Arqueologia nas cidades coloniais portuguesas, o exemplo de Salvador. In: ETCHEVARNE, Carlos; PIMENTEL, Rita (org.). Patrimônio arqueológico da Bahia. Salvador: SEI, 2011. p. 77-92. (Série Estudos e Pesquisas, n. 88).

ETCHEVARNE, Carlos. Aspectos da cerâmica colonial do século XVII, em Salvador, Bahia. Clio Arqueológica, Pernambuco, v. 1, n. 20, p. 53-79, 2006.

ETCHEVARNE, Carlos. Sítio Antiga Igreja da Sé. Relatório final da segunda etapa do plano de intervenção arqueológica. Salvador: Universidade Federal da Bahia, 2001.

FRANÇA, Jean Marcel Carvalho. A construção do Brasil na literatura de viagem dos séculos XVI, XVII e XVIII: antologia de textos, 15911808. Rio de Janeiro: José Olympio; São Paulo: UNESP, 2012.

HISSA, Sarah de Barros Viana. O petyn no cachimbo branco: arqueologia e fumo nos séculos XVII ao XIX. 2018. Tese (Doutorado em Arqueologia) - Museu Nacional, Universidade Federal do Rio de Janeiro, Rio de Janeiro, 2018.
HISSA, Sarah de Barros Viana; LIMA, Tania Andrade. Cachimbos europeus de cerâmica branca, séculos XVI ao XIX: parâmetros básicos para análise arqueológica. Anais do Museu Paulista: História e Cultura Material, São Paulo, v. 25, n. 2, p. 225268, maio/ago. 2017. DOI: http://dx.doi.org/10.1590/1982$02672017 v 25 n 0209$.

HUME, Ivor Noël. A guide to the artifacts of colonial America. Filadélfia: University of Pennsylvania Press, 2001.

LIRYO, Andersen. Saúde bucal em indivíduos sepultados no sítio arqueológico 'Igreja da Se', Salvador. 2003. Dissertação (Mestrado em Saúde Coletiva) - Universidade Federal do Rio de Janeiro, Rio de Janeiro, 2003.

MARCONDES, Renato Leite. $O$ mercado brasileiro do século XIX: uma visão por meio do comércio de cabotagem. Revista de Economia Política, São Paulo, v. 32, n. 1, p. 142-166, jan./mar. 2012. DOI: http://dx.doi.org/10.1590/S0101-31572012000100009.

MELLO, Evaldo Cabral de. O Brasil holandês. São Paulo: Companhia das Letras, 2010.

MELLO, José Antônio Gonsalves de. Tempo dos flamengos: influência da ocupação holandesa na vida e na cultura do Norte de Brasil. Recife: Massangana, 1987.

MENDONÇA, Teresa Cristina de Souza. Nuances da vida e da morte no cotidiano da cidade de Salvador da Bahia seiscentista: a busca de evidências em um estudo paleobiológico. 2012. Tese (Doutorado em Antropologia) - Universidade de Coimbra, Coimbra, 2012.

MENDONÇA, Teresa Cristina de Souza; ETCHEVARNE, Carlos. Evidências arqueológicas da saúde bucal em dois grupos populacionais da Salvador colonial. Revista Argentina de Antropologia Biológica, Argentina, v. 9, n. 2, p. 7-28, 2007.

MENEZES, José Luiz Mota. Atlas histórico-cartográfico do Recife. Recife: Massangana, 1988.

MIRANDA, Bruno Romero Ferreira. Doentes e incapazes para marchar: vida e morte no exército da Companhia Neerlandesa das Índias Ocidentais no Nordeste do Brasil, 1630-1654. História, Ciências, Saúde - Manguinhos, Rio de Janeiro, v. 22, n. 2, p. 337-353, abr./jun. 2015. DOI: http://dx.doi.org/10.1590/S010459702015000200003.

MIRANDA, Bruno Romero Ferreira. Sobre os que fazem a guerra: migração, origem e perfil social dos soldados do exército da companhia das índias ocidentais (1630-1654). Clio: revista de pesquisa histórica, Recife, v. 29, n. 2, p. 1-32, jul./dez. 2011.

NAJJAR, Rosana. Compra-se aterro! Um novo olhar sobre o Centro Histórico de Salvador. In: NAJJAR, Rosana (org.). Arqueologia do Pelourinho. Brasília: Programa Monumenta: IPHAN, 2010. p. 266-279. 
NASCIMENTO, Rômulo Luiz Xavier do. Entre os rios e o mar aberto: Pernambuco, os portos e o Atlântico no Brasil holandês. In: VIEIRA, Hugo Coelho; GALVÃO, Nara Neves Pires; SILVA, Leonardo Dantas (org.). Brasil holandês: história, memória e patrimônio compartilhado. São Paulo: Alameda, 2012. p. 193-222.

PERES, Fernando da Rocha. Memória da Sé. Salvador: Macunaíma, 1974.

PUNTONI, Pedro. No tempo dos flamengos: memória e imaginação. In: VIEIRA, Hugo Coelho; GALVÃO, Nara Neves Pires; SILVA, Leonardo Dantas (org.). Brasil holandês: história, memória e patrimônio compartilhado. São Paulo: Alameda, 2012. p. 31-46.

ROCHA, Heliana Faria Mettig. Visualização urbana digital: sistema de informações geográficas e históricas para o bairro do Comércio, Salvador. 2007. Dissertação (Mestrado em Arquitetura) - Universidade Federal da Bahia, Bahia, 2007.

RUSSELL-WOOD, John. Histórias do Atlântico português. São Paulo: UNESP, 2014.

SANTOS, Manuel Mesquita. A Sé Primacial do Brasil. Salvador: Gráfica da Bahia, 1933.

SCHOFIELD, John. Recent approaches in urban archaeology. In: SCHOFIELD, John; LEECH, Roger (ed.). Urban archaeology in Britain. London: The Council for British Archaeology, 1987. p. 1-8. (Research Report, n. 61).

SOUTH, Stanley. Method and theory in historical archeology. New York: Academic Press, 1977.

STASKI, Edward. Advances in urban archaeology. In: SCHIFFER, Michael B. (ed.). Advances in archaeological method and theory. New York: Academic Press, 1982. v. 5, p. 97-149.
STOLS, Eddy. Flamengos, holandeses e a sua aprendizagem na escravidão, séculos XVI e XVII. In: PAIVA, Eduardo França; ANASTASIA, Carla Maria Junho (ed.). O trabalho mestiço: maneiras de pensar e formas de viver - séculos XVI a XIX. São Paulo: Annablume, 2002. p. 41-61.

SUDBURY, Byron; GERTH, Ellen. The Jacksonville 'blue China' shipwreck (Site BA02): clay tobacco pipes. In: STEMM, Greg; KINGSLEY, Sean A. (ed.). Oceans Odyssey, 2: underwater heritage management e deep-sea shipwrecks in the English Channel \& Atlantic Ocean. Oxford, UK: Oxbow Books, 2011. p. 1-23. (Odyssey Marine Exploration Papers, 2).

SYMANSKI, Luís. Arqueologia de contrato em meio urbano no Brasil: algumas reflexões. Habitus: revista do Instituto Goiano de Pré-História e Antropologia, Goiás, v. 1, n. 1, p. 141-146, 2003.

TAVARES, Aurea Conceição Pereira. Vestígios materiais nos enterramentos na antiga Sé de Salvador: posturas das instituições religiosas africanas frente à igreja católica em Salvador no período escravista. 2006. Dissertação (Mestrado em Arqueologia) Universidade Federal de Pernambuco, Pernambuco, 2006.

VAINFAS, Ronaldo. Tempo dos flamengos: a experiência colonial holandesa. In: FRAGOSO, João; GOUVÊIA, Maria de Fátima. O Brasil colonial: 1580-1720. 2. ed. Rio de Janeiro: Civilização Brasileira, 2016. v. 2, p. 227-265.

VASCONCELOS, Thatiana Lima; SÁ, Lucilene Antunes Correia Marques de. A cartografia histórica da região metropolitana do Recife. In: SIMPÓSIO BRASILEIRO DE CARTOGRAFIA HISTÓRICA, 1., 2011, Paraty. Anais [...]. Paraty, 2011. p. 1-20. 
